\title{
Educação inclusiva e formação continuada de professores de Artes Visuais no Município de Cabedelo, Paraíba
}

\section{Inclusive education and continued training of teachers of Visual Arts in county of Cabedelo, Paraíba}

\author{
Robson Xavier da Costa \\ Doutor em Arquitetura e Urbanismo pela Universidade Federal do Rio Grande do Norte (UFRN) - \\ robsonxavierufpb@gmail.com - http://orcid.org/0000-0003-3012-3741 \\ Marinês Salviano Alves \\ Mestra em Artes Visuais pela Universidade Federal da Paraíba (UFPB) - marines-alves@hotmail.com - \\ http://orcid.org/0000-0001-7168-3273
}

\section{Resumo}

O estudo surgiu da necessidade de identificar o papel da Diretoria de Educação Inclusiva (DEI), da Secretaria de Educação do Município de Cabedelo (SEMC), Paraíba, na formação continuada do professor de Artes Visuais. Objetiva investigar se a formação continuada oferecida, no ano de 2015, pela DEI e pela SEMC para os professores de Artes Visuais, abordou temas sobre Educação Inclusiva, aplicados ao Ensino da Arte. Esta pesquisa foi realizada na DEI/SEMC; na Coordenação de Artes; na EMEF Elizabeth Ferreira da Silva e na EMEF Vereador Pedro Américo, as quais possuem Salas de Recursos Multifuncionais (SRM). Os dados foram obtidos por meio da observação direta, aplicação de questionários semiestruturados com os gestores e professores das instituições selecionadas e análise documental. O marco teórico envolve saberes do campo do Ensino da Arte, da formação do professor de Artes Visuais e da Educação Inclusiva. Os resultados obtidos destacaram que os professores de Artes Visuais pesquisados, começaram a se envolver com os conteúdos relativos à Inclusão Escolar por meio das ações promovidas pela DEI/SEMC.

Palavras-chave: Artes Visuais. Educação Inclusiva. Escola Pública.

\begin{abstract}
This study arose from the need to identify the role of the Board of Inclusive Education (DEI), from the Department of Education county of Cabedelo (SEMC), Paraíba, in the professor's continued formation of Visual Arts. Aims to investigate whether the continuing education offered by SEMC/DEl for the Visual Arts teachers in 2015 addressed themes on Inclusive Education, applied to Art Teaching. This research was carried out at DEI/SEMC; in the Arts Coordination; EMEF Elizabeth Ferreira da Silva and EMEF Vereador Pedro Américo, who have Multifunctional Resource Rooms (SRM). Data were obtained through direct observation, application of semistructured questionnaires with the managers and teachers of the selected institutions and documentary analysis. The theoretical framework involves knowledge of the field of Art Teaching, teacher training in Visual Arts and Inclusive Education. The results showed that the teachers of Visual Arts researched, began to get involved with the contents related to School Inclusion through the actions promoted by the DEI/SEMC. Keywords: Visual Arts. Inclusive Education. Public Schools.
\end{abstract}

Recebido em: 01/04/2018

Aceito em: 17/10/2018 


\section{INTRODUÇÃO}

A inclusão educacional representa um avanço no processo da educação escolar e diz respeito à aplicação da legislação vigente no Brasil e no mundo. As escolas inclusivas trabalham em busca da democratização do ensino, permitindo que os sistemas educacionais favoreçam a inclusão dos estudantes, sem distinção ou exclusão decorrente de alguma deficiência.

Dessa maneira, o Ensino das Artes, bem como as demais disciplinas curriculares, precisa de professores com capacidade pedagógica e metodológica para inserir os estudantes com deficiência no cotidiano escolar. Assim, buscamos refletir sobre a ampliação da participação do professor de Artes Visuais na Educação Inclusiva nas escolas que recebem estudantes com deficiências no Município de Cabedelo, Estado da Paraíba (PB).

Cabe destacar que a Educação Inclusiva representa uma orientação dominante da Declaração de Salamanca $(1994$, n. p.), que a definiu como "para todos e para cada um" e, também, responde à Lei Brasileira da Inclusão da Pessoa com Deficiência, por meio da Lei $n^{\circ} 13.146$, publicada em 06 de julho de 2018.

Esse estudo foi realizado no município de Cabedelo, na região metropolitana da João Pessoa, a capital paraibana. O Sistema Municipal de Educação do Município de Cabedelo, durante a pesquisa de campo, era composto por 36 instituições, são elas: Diretoria de Educação Inclusiva (DEI); 22 escolas ofertando as modalidades de Educação Infantil, Fundamental e Educação de Jovens e Adultos (EJA), das quais oito escolas possuíam Sala de Recursos Multifuncionais (SRM) em suas dependências físicas, estas salas estavam subordinadas à DEI; Associação Frei Gregório, onde atualmente funciona uma escola de Educação Infantil; um centro de Inclusão Escolar; nove Creches; um Centro de Artes e a Coordenação de Artes.

Por outro lado, a amostra desse estudo de caso foi composta por quatro instituições: a DEI, a Coordenação de Artes do Município e duas escolas municipais com SRM. Os instrumentos de construção dos dados foram observação direta e aplicação de questionários com a Coordenadora de Artes; a Diretora da DEl; dois gestores e dois professores de Artes Visuais das duas escolas participantes, totalizando seis sujeitos participantes.

A sede da DEl está localizada na Rua Siqueira Campos, s/n, no bairro de Camalaú, Cabedelo PB. Sua estrutura física engloba o Centro de Atendimento de Educação Especial (CAEE) Rafael 
Henrick França dos Santos, que desenvolve trabalho de apoio às escolas, em relação às demandas dos estudantes com deficiências. A Coordenação de Artes, da Secretaria de Educação do Município de Cabedelo (SEMC), não tem uma sede fixa, pois, nos últimos anos ocupou 03 espaços distintos, funcionando provisoriamente na Escola Municipal Damásio França de Macedo.

Este estudo buscou responder à seguinte questão de pesquisa: a formação continuada dos professores de artes, oferecida anualmente pela DEI e pela SEMC, aborda a aplicação de práticas pedagógicas inclusivas nas escolas da SEMC? Assim, objetivou verificar se os professores de Artes Visuais que participaram de capacitações disponibilizadas pela SEMC/DEI, desenvolvem práticas pedagógicas inclusivas nas escolas da SEMC.

Utilizamos os seguintes instrumentos para coleta de dados: observação direta e aplicação de questionários semiestruturados. Foram quatro questionários realizados: o primeiro composto por oito questões abertas respondidas pelos gestores das duas escolas municipais; o segundo com dez questões abertas aplicado com os professores de Artes Visuais das duas escolas participantes; o terceiro com nove questões abertas aplicado com a DEI e o quarto com seis questões abertas aplicado com a Coordenação de Artes de Cabedelo, PB.

\section{O ENSINO DA ARTE: BREVES CONSIDERAÇÕES}

A inclusão foi abordada na Constituição Brasileira de 1988, no capítulo III, da Educação, da Cultura e do Desporto, no seu artigo 205, ao prescrever que "a educação é direito de todos e dever do Estado e da Família” (BRASIL, 1988). No artigo 208, torna-se ainda mais específico: “[...] o dever do Estado com a educação será efetivado mediante a garantia de: [...] atendimento educacional especializado aos portadores de deficiência, preferencialmente na rede regular de ensino" (BRASIL, 1988).

No Brasil, ocorreram várias mudanças na nomenclatura de "pessoas excepcionais" para "pessoas com necessidades educacionais especiais", em 1986, por meio da Portaria CENESP/MEC, $\mathrm{n}^{\circ}$ 69. O termo "pessoas com necessidades educativas especiais começou a ser utilizado no final dos anos 1960, mas não foi capaz de modificar a concepção dominante" (CARDOSO, 2003, p. 19), atualmente o termo utilizado é Pessoa com Deficiência (PcD).

A Declaração de Salamanca, estabelecida em 10 de junho de 1994, na Espanha, foi definida em uma assembleia com os delegados da Conferência Mundial de Educação. Estavam 
representados 92 países e 25 organizações internacionais com o patrocínio do governo espanhol e da Organização das Nações Unidas para Educação, Ciência e Cultura (UNESCO, 1998). No encontro foi selado o compromisso com a Educação para Todos e elaborada a declaração conhecida por meio das metas de ação, objetivando efetivar na sociedade a Educação Inclusiva nos países participantes, incluindo o Brasil.

No Brasil, em 1996, foi promulgada a Lei de Diretrizes e Base da Educação Nacional (LDBEN) que enfatiza a educação inclusiva, no Capítulo V, no artigo 59: “[...] Os sistemas de ensino assegurarão aos educandos com necessidades especiais: currículos, métodos, técnicas, recursos educativos e organização específica para atender às suas necessidades" (BRASIL, 1996).

\footnotetext{
O tema inclusão é controverso sendo um processo que levará muito tempo, mas começou a fazer parte de discussões a partir da Declaração de Jomtiem e culminando na Declaração de Salamanca, onde o Brasil participou e assinou a Declaração, surgindo assim dentro da LDB no 9.394/96, vagas nas escolas regulares para PNEE. A Lei logicamente está aí para ser cumprida, mas o maior questionamento sobre isso é se realmente PPNE estão sendo incluídas verdadeiramente ou somente estão sendo colocadas "de corpo presente"? (SATO; CARDOSO; TOLOCKA, 2002, p. 21).
}

A concepção de Educação Inclusiva tornou-se uma política educacional nacional, objetivando inserir as PcD nas salas de aulas das escolas do Ensino Fundamental. Atualmente, no Brasil, inúmeras medidas legislativas atestam o direito de os alunos frequentarem as escolas regulares e o ensino formal, sem distinção ou exclusão (COSTA, 2010).

Faz-se necessário refletir sobre as demandas da inclusão dos estudantes com deficiências nas aulas de Artes Visuais. O contato do professor dessa disciplina com o cotidiano escolar dos estudantes com deficiências permite que ele perceba a necessidade de utilizar novos recursos no campo da motricidade, linguagem, mobilidade e produção artística, criando uma interlocução entre os campos da Educação Inclusiva e do Ensino de Artes Visuais.

Mantoan (2001) afirma que o processo inclusivo antecipa o uso de técnicas de ensino para atender a singularidade de cada estudante. É importante que o estudante compreenda quais são suas potencialidades e que o ensino se volte para um contexto que envolva desafios e possibilidades pedagógicas. 


\section{A DEI DA SECRETARIA DE EDUCAÇÃo DO MUNICÍPIO DE CABEDELO, PARAíBA.}

A cidade de Cabedelo, localizada no litoral paraibano, disponibiliza tanto para estudantes como para educadores, por meio da SEMC, o suporte da DEI, que dispõe do CAEE Rafael Henrick França dos Santos, desenvolvendo um trabalho de apoio às escolas, em relação às demandas dos estudantes com deficiências.

Algumas Escolas Municipais do Ensino Fundamental (EMEF) possuem uma SRM, que são subordinadas à DEl e definidas por meio da regulamentação do Ministério da Educação (MEC), com base no Decreto $n^{\circ}$ 7611/2011, que dispõe sobre as SRM, ao regulamentar que "são ambientes dotados de equipamentos, mobiliários e materiais didáticos e pedagógicos para a oferta do atendimento educacional especializado" (BRASIL, 2011) e, assegurar que as Secretarias Municipais de Educação devem suprir as respectivas especificidades pedagógicas dos estudantes com deficiências regularmente matriculados no ensino formal.

Os estudantes matriculados em escolas sem a SRM podem ser atendidos em outra escola que possua esse recurso didático inclusivo. O município de Cabedelo possui $22 \mathrm{EMEF}$ registradas na SEMC (PARAíBA, 2015), cuja relação está distribuída de acordo com o Quadro 01:

Quadro 01 - Relação das EMEF de Cabedelo

\begin{tabular}{|c|c|c|c|}
\hline & EMEF & DEFICIÊNCIA & QUANTIDADE \\
\hline 1 & Hildebrando da Silva & Intelectual & 2 \\
\hline \multirow{3}{*}{2} & \multirow{3}{*}{ Plácido de Almeida } & Intelectual & 6 \\
\hline & & Autismo & 1 \\
\hline & & Visual & 1 \\
\hline \multirow{4}{*}{3} & \multirow{4}{*}{ Vereador Pedro Américo } & Intelectual & 7 \\
\hline & & Auditiva & 2 \\
\hline & & Física & 1 \\
\hline & & TDAH & 2 \\
\hline \multirow{4}{*}{4} & \multirow{4}{*}{ Maria José de Miranda Burity } & Intelectual & 3 \\
\hline & & Síndrome de Down & 1 \\
\hline & & Física & 1 \\
\hline & & Autismo & 1 \\
\hline \multirow{4}{*}{5} & \multirow{4}{*}{ Adjuto Carlos de Morais } & Intelectual & 4 \\
\hline & & Autismo & 3 \\
\hline & & Síndrome de Down & 2 \\
\hline & & Hidrocefalia & 1 \\
\hline 6 & Edézio Rezende Pereira & Intelectual & 2 \\
\hline
\end{tabular}


Educação inclusiva e formação continuada de professores de Artes Visuais no Município de Cabedelo, Paraíba

Robson Xavier da Costa, Marinês Salviano Alves

\begin{tabular}{|c|c|c|c|}
\hline & & Autismo & 2 \\
\hline \multirow{3}{*}{7} & \multirow{3}{*}{ Agripino José de Morais } & Intelectual & 8 \\
\hline & & Autismo & 1 \\
\hline & & Esquizofrenia & 2 \\
\hline \multirow{5}{*}{8} & \multirow{5}{*}{ João Roberto Borges de Souza } & Intelectual & 8 \\
\hline & & Autismo & 4 \\
\hline & & Síndrome de Down & 1 \\
\hline & & Auditiva & 1 \\
\hline & & Física & 1 \\
\hline \multirow{10}{*}{9} & \multirow{10}{*}{ Paulino Siqueira } & Intelectual & 10 \\
\hline & & Autismo & 7 \\
\hline & & Auditiva & 4 \\
\hline & & Síndrome de Down & 1 \\
\hline & & Dislexia & 1 \\
\hline & & Esquizofrenia & 1 \\
\hline & & Hidrocefalia & 1 \\
\hline & & TDAH & 1 \\
\hline & & Visual & 1 \\
\hline & & Mielomeningocele & 1 \\
\hline 10 & Rosa Figueiredo de Lima & Intelectual & 2 \\
\hline 11 & Maria Pessoa Cavalcante & - & - \\
\hline \multirow{3}{*}{12} & \multirow{3}{*}{ Antônio Viana da Silva } & Intelectual & 5 \\
\hline & & Autismo & 2 \\
\hline & & TDAH & 1 \\
\hline \multirow{2}{*}{13} & \multirow{2}{*}{ Damásio França de Macedo } & Intelectual & 2 \\
\hline & & TDAH & 2 \\
\hline 14 & Major Adolfo Pereira Maia & Intelectual & 6 \\
\hline 15 & Maria das Graças Carlos Rezende & - & - \\
\hline 16 & Elizabeth Ferreira da Silva & Intelectual & 4 \\
\hline \multirow{2}{*}{17} & \multirow{2}{*}{ Centro Integrado Imaculada Conceição } & Intelectual & 1 \\
\hline & & Auditiva & 2 \\
\hline 18 & Silvana Oliveira Pontes & Intelectual & 2 \\
\hline \multirow{2}{*}{19} & \multirow{2}{*}{ Maria José Veríssimo de Andrade } & Intelectual & 9 \\
\hline & & Síndrome de Down & 2 \\
\hline 20 & Marizelda Lira da Silva & Intelectual & 3 \\
\hline \multirow{5}{*}{21} & \multirow{5}{*}{ Altimar de Alencar Pimentel } & Intelectual & 6 \\
\hline & & Autismo & 5 \\
\hline & & Dislexia & 1 \\
\hline & & TDAH & 2 \\
\hline & & Dificuldade na fala & 1 \\
\hline \multirow{2}{*}{22} & \multirow{2}{*}{ Edlene de Oliveira Barbosa } & Intelectual & 2 \\
\hline & & Física & 2 \\
\hline
\end{tabular}

Fonte: adaptado de Alves (2016). 
De acordo com o Quadro 01, foi identificado no ano de 2015 a existência de 158 crianças e adolescentes com deficiências, regularmente matriculadas nas 22 unidades de ensino. Os dados evidenciam a incidência de 12 tipos de deficiências identificados no alunado, cuja maioria é diagnosticada com déficit intelectual, ou seja, 92 alunos e, por sua vez, foram constatados a existência de 26 estudantes diagnosticados com autismo.

Entre as 22 escolas de Ensino Fundamental de Cabedelo, apenas três não tinham estudantes com deficiências regularmente matriculados, nas outras 19 instituições foram registradas estudantes com deficiências (Quadro 01). Ou seja, verificou-se que nove escolas têm estudantes com Deficiência Auditiva, com Transtorno de Déficit de Atenção e Hiperatividade (TDAH) foram observados alunos matriculados em oito escolas. Enquanto que sete escolas tinham alunos com Síndrome de Down, apenas cinco instituições com alunos com Deficiência Física.

Por outro lado, dentre os alunos matriculados nas 22 escolas do Ensino Fundamental de Cabedelo, três estudantes foram diagnosticadas com Esquizofrenia, também foi constatado dois estudantes matriculados com Deficiência Visual, Hidrocefalia e Dislexia; e um estudante com Mielomeningocele e Dificuldade na Fala.

Nem todas as escolas de Ensino Fundamental da SEMC disponibilizavam cuidadores ou intérpretes aos estudantes com deficiências, e nem todos os estudantes recebiam atendimento externo. A EMEF Altimar Pimentel possuía, em 2015, sete estudantes acompanhados em sala de aula por cuidadores/intérpretes. Vale ressaltar que as $22 \mathrm{EMEF}$ recebem o apoio da equipe da DEI para desenvolver seus trabalhos pedagógicos, educativos e inclusivos, dividindo-as em grupos.

A equipe da DEI que atendia as escolas do município paraibano de Cabedelo era composta por uma equipe multiprofissional (Quadro 02), contando com: pedagogos, psicólogos, psicopedagogos, arte/educadores, fonoaudiólogos e assistentes sociais. Esses profissionais deslocavam-se até as escolas e faziam reuniões com gestores, supervisores e professores para explanarem as vivências cotidianas, no intuito de colaborar com encaminhamentos para atender a demanda dos professores em relação aos estudantes com deficiências. Para uma melhor visualização, a disponibilidade da equipe técnica da DEI encontra-se distribuída no Quadro 02. 
Educação inclusiva e formação continuada de professores de Artes Visuais no Município de Cabedelo,

Paraíba

Robson Xavier da Costa, Marinês Salviano Alves

Quadro 02 - Histórico quantitativo Equipe técnica da DEI de Cabedelo

\begin{tabular}{|l|c|c|c|c|c|c|c|c|}
\hline \multicolumn{1}{|c|}{ Profissional/Ano } & 2005 & 2006 & 2007 & 2008 & 2009 & 2010 & 2011 & 2012 \\
\hline Arte /educador & 1 & 2 & 2 & 3 & 3 & 3 & 3 & 2 \\
\hline Assistente Social & 0 & 2 & 2 & 2 & 2 & 2 & 2 & 2 \\
\hline Coordenador & 2 & 1 & 1 & 2 & 1 & 1 & 1 & 1 \\
\hline Cuidador & 0 & 0 & 0 & 0 & 1 & 8 & 15 & 23 \\
\hline Fonoaudiólogo & 2 & 3 & 4 & 4 & 3 & 3 & 3 & 3 \\
\hline Intérprete de LIBRAS & 2 & 3 & 9 & 9 & 10 & 11 & 12 & 14 \\
\hline Instrutores & 0 & 0 & 0 & 0 & 0 & 1 & 1 & 1 \\
\hline Pedagogo & 4 & 7 & 7 & 7 & 8 & 8 & 8 & 11 \\
\hline Professores de SRM & 0 & 0 & 1 & 5 & 6 & 7 & 9 & 12 \\
\hline $\begin{array}{l}\text { Professores de } \\
\text { LIBRAS }\end{array}$ & 0 & 0 & 1 & 1 & 2 & 2 & 2 & 2 \\
\hline Psicólogo & 0 & 1 & 1 & 2 & 2 & 2 & 2 & 2 \\
\hline Psicólogo em SRM & 0 & 0 & 0 & 1 & 1 & 1 & 1 & 1 \\
\hline Secretária & 1 & 0 & 0 & 1 & 1 & 1 & 0 & 1 \\
& & & & & & & & \\
\hline
\end{tabular}

Fonte: adaptado de Paraíba (2015).

De acordo com o Quadro 02, identificamos que ao longo dos anos a DEI aumentou o número de profissionais da sua equipe técnica, expandindo a sua diversidade. No ano de 2005 , a equipe era formada por apenas 13 profissionais, em 2012 o número da equipe foi ampliado para 76. No ano de 2005, a DEI não possuía assistente social, cuidador, instrutor, professor de libras e psicólogo nas SRMs.

As SRMs vinculadas à DEI e estruturadas nas EMEF de Cabedelo foram implantadas no intuito de "(...) de promover as condições de acesso, participação e aprendizagem dos estudantes, público alvo da educação especial no ensino regular (BRASIL, 2012, p. 3).

Em conformidade com a Resolução CNE/CEB n 4/2009, que "institui diretrizes operacionais para o atendimento educacional especializado na educação básica, modalidade educação especial" (BRASIL, 2009), a SEMC divulgou o mapeamento das EMEF que possuem a SRM para atender aos estudantes com deficiências, público alvo do AEE. A distribuição das SRMs pode ser visualizada no Quadro 03. 
Educação inclusiva e formação continuada de professores de Artes Visuais no Município de Cabedelo,

Paraíba

Robson Xavier da Costa, Marinês Salviano Alves

Quadro 03 - Quantitativo dos estudantes atendidos nas SRM de Cabedelo

\begin{tabular}{|c|c|c|c|}
\hline & ESCOLA MUNICIPAL & ALUNO & DEFICIÊNCIA \\
\hline \multirow{4}{*}{1} & \multirow{4}{*}{ Paulino Siqueira } & \multirow{4}{*}{5} & Intelectual (2) \\
\hline & & & Autismo \\
\hline & & & Física \\
\hline & & & Surdez \\
\hline 2 & Hildebrando das Silva & - & - \\
\hline \multirow{3}{*}{3} & \multirow{3}{*}{ Edézio Rezende } & \multirow{3}{*}{9} & Autismo (2) \\
\hline & & & Intelectual (6) \\
\hline & & & Física, Intelectual e Motora \\
\hline 4 & Pedro Américo & - & - \\
\hline 5 & Maria José Veríssimo Andrade & 10 & Intelectual (10) \\
\hline \multirow{2}{*}{6} & \multirow{2}{*}{ Adjuto Carlos de Morais } & \multirow{2}{*}{6} & Intelectual (2) \\
\hline & & & Autismo (4) \\
\hline \multirow{4}{*}{7} & \multirow{4}{*}{ João Roberto Borges de Souza } & \multirow{4}{*}{14} & Intelectual (10) \\
\hline & & & Autismo (2) \\
\hline & & & Surdez \\
\hline & & & Física \\
\hline 8 & Elizabeth Ferreira da Silva & - & - \\
\hline
\end{tabular}

Fonte: adaptado de Alves (2016).

De acordo com o Quadro 03, apenas oito escolas da SEMC contavam com SRM para atender aos estudantes com deficiências/dificuldades de aprendizagem, regularmente matriculados na SEMC. Mas, vale destacar que a Educação Infantil no município também recebe estudantes com deficiências.

De acordo com o Quadro 04, a Educação Infantil de Cabedelo atendeu um total de 18 crianças com deficiências em oito unidades educacionais no ano de 2015. Porém, nenhuma dessas crianças foi acompanhada por cuidadores ou intérpretes, nem recebeu algum tipo de atendimento externo especializado.

Na concepção da Educação Inclusiva, o processo educacional é compreendido como um todo, pressupondo a implementação de políticas públicas estruturantes no sistema de ensino. Segundo Costa (2010), por vezes supera os modelos de integração em classes especiais e, além de cumprir sua função social, o sistema educacional deve construir uma proposta pedagógica que valorize a diversidade, ofertando a escolarização em classes comuns do ensino regular e o atendimento às necessidades educacionais específicas dos seus educandos. 
Educação inclusiva e formação continuada de professores de Artes Visuais no Município de Cabedelo,

Paraíba

Robson Xavier da Costa, Marinês Salviano Alves

Quadro 04 - Quantitativo dos estudantes com deficiências na Educação Infantil de Cabedelo PB

\begin{tabular}{|c|c|c|c|}
\hline & INSTITUIÇÃO & QUANTIDADE & DEFICIÊNCIA \\
\hline 1 & Creche Alexia Luana & 2 & Auditiva (1); Física (1) \\
\hline 2 & Creche Santa Catarina & 2 & $\begin{array}{c}\text { Atraso no DNPM e } \\
\text { Física }\end{array}$ \\
\hline 3 & Creche Pequena Princesa & 1 & Autismo \\
\hline 4 & Creche Josefa de Medeiros Regis & 1 & Síndrome de Asperger \\
\hline 5 & $\mathrm{CIE}$ & 1 & $\begin{array}{c}\text { Atraso DNPM e } \\
\text { Intelectual }\end{array}$ \\
\hline 6 & Creche Silvana de Oliveira & 2 & Intelectual (2) \\
\hline \multirow{4}{*}{7} & \multirow{4}{*}{ Associação Frei Gregório } & \multirow{4}{*}{6} & Autismo (3) \\
\hline & & & Intelectual \\
\hline & & & DMU, Autismo e Física \\
\hline & & & DNPM e Física \\
\hline 8 & Creche Tarik Anthony Mais Azevedo & 3 & Paralisia Cerebral (3) \\
\hline
\end{tabular}

Fonte: adaptado de Alves (2016).

Essa concepção pode ser verificada nas Diretrizes Nacionais da Educação Básica, estabelecidas pela Resolução CNE/CEB n 4/2010, segundo disposto no seu Parágrafo $1^{\circ}$ do artigo 29:

$\S 1$ 을 Os sistemas de ensino devem matricular os estudantes com deficiência, transtornos globais do desenvolvimento e altas habilidades/superdotação nas classes comuns do ensino regular e no atendimento educacional especializado (AEE), complementar ou suplementar à escolarização ofertado em sala de recursos multifuncionais ou em centros de AEE da rede pública ou de instituições comunitárias, confessionais ou filantrópicas sem fins lucrativos (BRASIL, 2012).

Os sistemas de ensino devem matricular além dos estudantes com deficiências, aqueles que apresentam transtornos globais do desenvolvimento e altas habilidades/superdotação nas classes comuns do ensino regular e no Atendimento Educacional Especializado (AEE). O objetivo deste atendimento é identificar habilidades e necessidades dos estudantes, organizar recursos de acessibilidade e realizar atividades pedagógicas específicas que promovam seu acesso ao currículo.

A DEI de Cabedelo objetiva acompanhar os estudantes com deficiências matriculados na rede municipal de ensino, por meio das SRMs. A interação entre a DEI e os professores e/ou pela direção das escolas tem como foco o comportamento dos alunos em sala de aula, a partir de então, começam as avaliações individuais. As avaliações ocorrem durante o período em que os estudantes estão na escola e são feitos em comum acordo com professores, com a autorização dos pais ou 
Educação inclusiva e formação continuada de professores de Artes Visuais no Município de Cabedelo,

Paraíba

Robson Xavier da Costa, Marinês Salviano Alves

responsáveis, geralmente, agendadas previamente, para que o professor tenha tempo para planejar a aula de modo que o estudante não se prejudique por estar fora de sala.

Após a avaliação, os profissionais da equipe se reúnem para encaminhar quais serão os atendimentos especializados que o estudante necessitaria. Verificamos que a equipe conta com o apoio da SEMC, para os encaminhamentos externos - disponibilização de transporte para o estudante ir acompanhado pelo responsável para consultas médicas, bem como, possibilita que as assistentes sociais se locomovam para marcar consultas. Às vezes, os deslocamentos são para João Pessoa, de acordo com as necessidades cotidianas, ou seja, não se restringindo só ao âmbito de Cabedelo.

Segundo a coordenadora da equipe, a pedagoga Socorro Feitosa, entrevistada no dia 26 de novembro de 2015, os estudantes com deficiências encaminhados ao DEI são acompanhados pela assistente social da equipe, e toda a documentação sobre o estudante, desde encaminhamento pelo professor até a identificação da sua dificuldade fica arquivada na sede da DEl. Os profissionais que fazem as avaliações escrevem relatórios e cada estudante tem uma pasta que é disponibilizada para futuras consultas. Segundo relatos da coordenadora do DEI, vários estudantes conseguiram laudo médico para diagnosticar deficiências que as famílias, por motivos variados, não haviam identificado, possibilitando acessar o Benefício de Prestação Continuada (BPC), melhorando sua qualidade de vida e, consequentemente, refletindo diretamente no rendimento escolar.

Além do suporte para os estudantes, a equipe procura dar apoio aos professores durante dois meses, com troca de experiências, no mesmo período em que a escola está sendo atendida pela equipe da DEl através de dois encontros anuais de formação realizados no auditório localizado na SEMC. No primeiro encontro anual, a "sensibilização" é trabalhada por meio de questões de cunho psicológico, com a participação de todo o corpo docente e servidores das escolas. O segundo encontro aborda propostas de ensino-aprendizagem para PcD. Apesar do pouco tempo, apenas dois encontros anuais, segundo a Coordenadora da DEI, os professores tiram dúvidas e recebem sugestões de atividades e práticas que podem favorecer o cotidiano nas escolas.

Ademais da formação específica, verificamos que vários profissionais da DEI, a exemplo da coordenadora, possuem formação especializada em inclusão social. A equipe conta com alguns especialistas em AEE, estes trabalham no atendimento nas SRMs, nas escolas. De acordo com os dados levantados a partir da aplicação dos questionários semiestruturados nesta pesquisa, a equipe 
tem passado por reformulações ao longo dos anos. Cada coordenador imprimiu algo novo ao trabalho, cuja atual coordenação atua ao longo de uma década.

Portanto, na análise dos relatos por meio dos questionários respondidos e dos documentos analisados, a DEI mantém uma coerência no trabalho desenvolvido e na observância dos seus objetivos, tais como:

\footnotetext{
- Minimizar as desigualdades existentes entre os alunos e promover a Inclusão Educacional de forma abrangente, ou seja, aceitar o aluno como ele é, respeitando suas peculiaridades e estimulando suas potencialidades;

- Identificar alunos com necessidades educacionais especiais, para em seguida, prestar atendimentos internos (acompanhados pela equipe multiprofissional do projeto) e externos (instituições especializadas parceiras) de forma que minimizem os danos causados por determinadas dificuldades e/ou deficiências;

- Assegurar a permanência do aluno na escola, prestando um serviço de qualidade, livre de qualquer tipo de exclusão;

- Promover formações e sensibilizações para os profissionais das escolas atendidas, na área de educação especial/inclusiva (ARRUDA, 2012, p. 18).
}

Destacamos as mudanças que ocorreram nos últimos anos na estrutura física da DEI, uma vez que depois de funcionar por vários anos dentro da SEMC, atualmente possui sede própria, o que possibilitou o atendimento aos estudantes com deficiências, que antes contavam apenas com avaliação e encaminhamento. Durante o período da pesquisa o atendimento pela equipe da DEI era realizado no horário oposto ao que o estudante estava matriculado na escola regular, agendado previamente e abrangendo as entrevistas da equipe com os familiares.

A família é outro ponto observado durante todo o processo. A equipe marcava horário para entrevistas individuais com familiares ou responsáveis pelas crianças encaminhadas, realizadas pelo psicólogo da equipe, acompanhado por outro profissional. As entrevistas objetivavam colher dados para conhecer o histórico de vida do estudante com deficiências. Em um segundo momento, dependendo da avaliação, a equipe procurava orientar a família, de modo a ajudar na educação dos estudantes.

Também foi realizada pela DEI na escola uma reunião de pais no intuito de abordar temas relevantes, tais como: direitos e benefícios da criança com deficiências; a importância dos cuidados básicos; acompanhamento da vida escolar, entre outros. Nesse momento pedagógico com os pais, a equipe da DEI ficava à disposição para atender situações emergenciais ou esclarecer dúvidas. Por vezes, crianças vítimas de violência ou envolvidas em situações de risco suscitam a necessidade de uma intervenção imediata. Nesses casos, alguns membros da equipe fazem uma reunião para 
identificar o problema e decidem em conjunto as medidas a serem adotadas em cada situação específica.

Os resultados obtidos nessa pesquisa possibilitaram identificar, por meio da observação da prática docente no Ensino Fundamental do município de Cabedelo e da tabulação dos dados disponibilizados, as ações implementadas pela SEMC, por meio da DEI e da Coordenação Municipal de Arte, objetivando promover a inclusão educacional no município.

$\mathrm{Na}$ segunda fase da pesquisa, final de 2015 e início de 2016, realizamos entrevistas semiestruturadas com os professores de Artes Visuais das EMEF Elizabeth Ferreira da Silva (Escola A) e EMEF Vereador Pedro Américo (Escola B), evidenciando suas práticas pedagógicas inclusivas em sala de aula, no intuito de entender como a Educação Inclusiva tem se efetivado nas práticas docentes desses profissionais da Educação.

Os dados foram coletados por meio da realização de entrevistas, observação de aulas, acompanhamento de planejamentos e dos encontros realizados com a DEl. As descrições das duas escolas pesquisadas de Cabedelo estão dispostas no Quadro 05.

Quadro 05 - Panorama geral das escolas pesquisadas no Município de Cabedelo PB

\begin{tabular}{|c|c|c|c|c|c|c|}
\hline EMEF & TURNOS & NÍVEIS & ALUNOS & $\begin{array}{c}\text { ALUNOS } \\
\text { COM } \\
\text { DEFICIÊNCIA }\end{array}$ & PROFESSORES & FUNCIONÁRIOS \\
\hline $\begin{array}{c}\text { Elizabeth } \\
\text { Ferreira } \\
\text { da Silva }\end{array}$ & $\begin{array}{c}\text { Manhã, } \\
\text { Tarde e } \\
\text { Noite }\end{array}$ & $\begin{array}{c}\text { Fundamental, } \\
\text { EJA }\end{array}$ & 650 & 5 & 34 & 30 \\
\hline $\begin{array}{c}\text { Vereador } \\
\text { Pedro } \\
\text { Américo }\end{array}$ & $\begin{array}{c}\text { Manhã, } \\
\text { Tarde e } \\
\text { Noite }\end{array}$ & $\begin{array}{c}\text { Fundamental, } \\
\text { EJA }\end{array}$ & 630 & 10 & 45 & 19 \\
\hline \multicolumn{3}{|c|}{ Total } & 1280 & 15 & 79 & 49 \\
\hline
\end{tabular}

Fonte: adaptado de Alves (2016).

De acordo com o Quadro 05, entre os 1280 estudantes das duas escolas, 15 possuem algum tipo de deficiência. Foram entrevistados dois, dos 79 professores das escolas, docentes de Artes Visuais do Ensino Fundamental, um de cada escola, denominados nessa pesquisa de Professor A e Professor B. Segundo informações obtidas em entrevista realizada no dia 09 de dezembro de 2015, com a Fonoaudióloga da equipe, os profissionais se reuniram semanalmente para discutir e 
planejar suas ações. Durante os meses de fevereiro e dezembro os respectivos profissionais permaneceram atuando na sede da DEI para planejar e avaliar o trabalho desenvolvido.

Vale salientar que, em prol do atendimento integral da população de Cabedelo, a DEI trabalha em parceria com outros órgãos públicos, tais como: Secretaria de Ação Social, que viabiliza cestas básicas, óculos, moradia entre outros; Secretaria de Saúde de Cabedelo - Policlínica, Programa de Saúde da Família (PSF) e, atendimento médico em João Pessoa, no Hospital Universitário Lauro Wanderley, Hospital Estadual Edson Ramalho, Hospital Arlinda Marques; Fundação Centro Integrado de Apoio ao Portador de Deficiência - reabilitação de estudantes com deficiências; Centro Universitário de João Pessoa - psicoterapias; Centro de Referência Especializado de Assistência Social (CREAS), Programa de Erradicação do Trabalho Infantil (PETI), Programa de Atenção Integral à Família (PAIF), Projeto Sentinela e Conselhos Tutelares - proteção à criança e adolescente; Instituto Nacional do Seguro Social (INSS) - Aquisição de Benefício de Prestação Continuada para alunos com deficiência que tem direito ao benefício.

\section{COORDENAÇÃO DE ARTES: MAPEAMENTO DOS PROFESSORES DE ARTES DA SEMC}

A SEMC, com suas 22 instituições escolares, que além do Ensino Fundamental disponibilizam o Ensino Infantil e a Educação de Jovens e Adultos (EJA), cujo processo de Educação Inclusiva municipal, também, disponibiliza uma Associação conhecida por Frei Gregório, onde funciona uma escola de Ensino Infantil; um Centro de Inclusão Escolar; nove Creches e um Centro de Artes.

O Quadro 06 evidencia que em 2015 a SEMC contava com 55 professores de Artes, 32 atuando nas Escolas Municipais, sendo um professor na Associação Frei Gregório e outro na equipe de Inclusão Escolar, bem como quatro professores nas Creches e 17 no Centro de Artes. Se destaca que entre os 55 profissionais, 21 são habilitados em Artes Visuais (representando aproximadamente 38\% da amostra) - 16 professores em Música, 12 em Teatro e três em Dança.

Em 2015, o Centro de Artes de Cabedelo tinha na equipe 17 professores, 11,7\% habilitados em Artes Visuais e 53\% habilitados na área de Música. A maioria dos professores efetivos de Artes da SEMC são vinculados às Escolas Municipais e ao Centro de Artes. 
Quadro 06 - Quantitativos da SEMC.

\begin{tabular}{|c|c|c|c|c|c|c|}
\hline INST. EDUC. & QNT & ENSINO & TURNO & $\begin{array}{l}\text { PROF. } \\
\text { ARTES }\end{array}$ & HABILIDADE & QNT \\
\hline \multirow{3}{*}{ Escolas Municipais } & \multirow{3}{*}{22} & \multirow{3}{*}{$\begin{array}{c}\text { Infantil; } \\
\text { Fundamental I e } \\
\text { II; EJA }\end{array}$} & \multirow{3}{*}{$\begin{array}{c}\text { Manhã; } \\
\text { Tarde; Noite }\end{array}$} & \multirow{3}{*}{32} & Música & 6 \\
\hline & & & & & Teatro & 9 \\
\hline & & & & & Visuais & 17 \\
\hline Associação & 1 & Infantil & $\begin{array}{c}\text { Manhã; } \\
\text { Tarde }\end{array}$ & 1 & Música & 1 \\
\hline Inclusão Escolar & 1 & - & $\begin{array}{l}\text { Manhã; } \\
\text { Tarde }\end{array}$ & 1 & Teatro & 1 \\
\hline \multirow{3}{*}{ Creche } & \multirow{3}{*}{9} & \multirow{3}{*}{ Infantil } & \multirow{3}{*}{$\begin{array}{l}\text { Manhã; } \\
\text { Tarde }\end{array}$} & \multirow{3}{*}{4} & Dança & 1 \\
\hline & & & & & Teatro & 1 \\
\hline & & & & & Visuais & 2 \\
\hline \multirow{4}{*}{ Centro de Artes } & \multirow{4}{*}{1} & \multirow{4}{*}{-} & \multirow{4}{*}{$\begin{array}{l}\text { Manhã, } \\
\text { Tarde }\end{array}$} & \multirow{4}{*}{17} & Dança & 2 \\
\hline & & & & & Visuais & 2 \\
\hline & & & & & Teatro & 4 \\
\hline & & & & & Música & 9 \\
\hline
\end{tabular}

Fonte: adaptado de Alves (2016).

A Coordenação do Centro de Artes do Município de Cabedelo, anualmente, ministra capacitação e formação continuada, para os professores efetivos e contratados. A coordenação também faz visitas periódicas nas instituições com o objetivo de acompanhar o trabalho dos professores, o rendimento dos estudantes com deficiências, por meio das notas e frequências, além dos registros diários. Segundo a Coordenação do Centro de Artes da SEMC a formação continuada:

É ministrada pelos próprios professores da rede com cerca de $80 \%$ prática e $20 \%$ teórica. Este ano de 2015 essa formação quase não aconteceu devido o Centro de Artes (local dessa Formação) sofrer mudança de local de funcionamento e pelo local instalado não oferecer espaço (FEITOSA, 2015).

Identificamos que os profissionais que atuam nas SRMs recebem formação continuada para educação inclusiva, "os demais profissionais não recebem nenhum tipo de apoio ou qualquer outra assistência pela equipe de inclusão, mesmo tendo em suas salas, alunos que necessitem de cuidados especiais" (FEITOSA, 2015).

Por outro lado, os dois professores de Artes Visuais pesquisados, ao serem questionados se conheciam a DEI do município de Cabedelo, responderam:

Professor B "- Sim, já atuei por cinco anos com o grupo, observando que fazem um trabalho diferencial para o município" (PROFESSOR B, 2016);

Professor A "- Já ouvi falar, mas não conheço" (PROFESSOR A, 2016). 
Ao serem questionados se participaram de alguma formação continuada que abordava a educação inclusiva, oferecida pela SEMC relataram que:

Professor A "- houve um curso de LIBRAS que participei" (PROFESSOR A, 2016);

Professor B "- sim, há formações e acompanhamentos" (PROFESSOR B, 2016).

De acordo com os relatos da Coordenadora do Centro de Arte, as políticas de inclusão escolar determinam que:

As instituições devem estar preparadas para incluir a todos, independentemente do tipo de deficiência que o aluno possui, deve oferecer também sala de recurso e sala de interatividade, professores qualificados e cuidadores que venham acompanhar e trabalhar no desenvolvimento da criança (FEITOSA, 2015).

Porém, ela destaca que "até o presente momento não recebi nenhum tipo de formação oferecida pelo setor de Inclusão Escolar do nosso município" (FEITOSA, 2015), evidenciando que a maioria dos professores de Artes da SEMC tem estudantes com deficiências em suas salas regulares. E, segundo Feitosa (2015), “em nossas escolas já é realidade a presença de um grande número de alunos com tipos de deficiências e graus diversificados".

Nessa perspectiva, percebe-se que a maioria dos professores de Artes de Cabedelo, leciona para estudantes com deficiências em salas regulares, representando um desafio para legitimar, de fato, a Educação Inclusiva na educação básica da rede pública municipal.

\section{CONSIDERAÇÕES FINAIS}

O ensino de Artes Visuais no contexto da inclusão social pode ser um caminho para proporcionar a inclusão e a democratização do acesso à educação, evitando qualquer tipo de segregação. A passagem da teoria à prática da educação inclusiva no Ensino Fundamental apresenta-se como um desafio para encontrar um caminho para a construção de um espaço escolar que receba a todos, sem distinção, aceitando as diferenças.

As escolas municipais de Cabedelo são assistidas por uma equipe multidisciplinar de inclusão social a DEI, cuja SEMC disponibiliza cursos de formação continuada aos professores, alguns deles abordam temas sobre a inclusão dos estudantes com deficiências, porém, nem todos os professores entrevistados nesta pesquisa conhecem a DEI. 
A DEI do Município de Cabedelo investe na formação continuada em prol da Educação Inclusiva, pois a ausência de informação sobre essa área pode dificultar o trabalho do professor com estudantes com deficiências em sala regular.

Ao final deste estudo concluímos que quando os professores de Artes, do Ensino Fundamental, não se sentem capacitados para receberem os estudantes com deficiências e/ou síndromes nas salas regulares, da educação formal, podem comprometer a eficácia do processo ensino-aprendizagem e contribuir para a evasão escolar. O ambiente escolar inclusivo possibilita oportunidades e desafios para novas aprendizagens, não apenas para os estudantes, mas também, para os professores que também precisam de formação continuada, para desenvolverem suas habilidades e competências.

Por sua vez, o professor da SRM favorece a aprendizagem inclusiva e propicia aos estudantes recursos que os auxiliarão nas disciplinas curriculares, representando um importante aliado dos demais professores, por ter recebido qualificação específica para exercer esta função dentro da escola e ter especial atenção com os recursos educacionais inclusivos. Nessa perspectiva, a inclusão educacional ainda esbarra nos desafios que permeiam a escola regular ao tentar inserir, de fato, os estudantes com deficiências no processo de ensino-aprendizagem da básica nacional. Pois, percebemos que tanto as escolas quanto os educadores têm como referências um currículo que, muitas vezes, não favorece a diversidade.

\section{REFERÊNCIAS}

ALVES, Marines Salviano. 0 ensino de arte e a educação inclusiva: um estudo de caso com os professores na rede municipal de Cabedelo - PB. 2016. Dissertação (Mestrado em Artes Visuais) Centro de Comunicação, Turismo e Artes, Universidade Federal da Paraíba, João Pessoa, 2016. Disponível em: https://repositorio.ufpb.br/jspui/handle/123456789/11529. Acesso em: 16 jul. 2019.

ARRUDA (org.). Educação inclusiva: do sonho à realidade. Cabedelo: Secretaria de Educação, 2012.

BRASIL. [Constituição (1988)]. Constituição da República Federativa do Brasil de 1988. Brasília, DF: Presidência da República, [2016]. Disponível em: http://www.planalto.gov.br/ccivil_03/constituicao/constituicao.htm. Acesso em: 10 jul. 2019.

BRASIL. Decreto $n^{\circ}$ 7.611, 17 de novembro de 2011. Dispõe sobre a educação especial, o atendimento educacional especializado e dá outras providências. Brasília, DF, 17 nov. 2011. 
Disponível em: http://www.planalto.gov.br/ccivil_03/_ato2011-2014/2011/decreto/d7611.htm. Acesso em: 10 jul. 2019.

BRASIL. Documento orientador Programa Implantação de Salas de Recursos Multifuncionais. Brasília: MEC, 2012. Disponível em: http://portal.mec.gov.br/index.php? option=com_docman\&view=download\&alias=11037-doc-orientador-multifuncionaispdf\&Itemid=30192. Acesso em: 12 jul. 2019.

BRASIL. Lei no 9.394, de 20 de dezembro de 1996. Estabelece as diretrizes e bases da educação nacional. Brasília, DF, 20 dez. 1996. Disponível em:

http://www.planalto.gov.br/ccivil_03/leis/I9394.htm. Acesso em: 10 jul. 2019.

BRASIL. Resolução CNE/CEB no 4/2009 - CNE/MEC. Disponível em: http://portal.mec.gov.br/dmdocuments/rceb004_09.pdf. Acesso em: 03 set. 2017.

CARDOSO, Marlene da Silva. Aspectos históricos da educação especial: da exclusão à inclusão uma longa caminhada. In: MOSQUERA, Juan José Mouriño; STOBAÜS, Claus Dieter (org.). Educação especial: em direção à educação inclusiva. Porto Alegre: EDIPUCRS, 2003.

COSTA, Robson Xavier (org.). Arteterapia \& educação inclusiva: diálogos multidisciplinares. Rio de Janeiro: WAK, 2010.

DECLARAÇÃO de Salamanca: Sobre princípios políticas e práticas na área das necessidades educativas especiais. Salamanca, 1994. Disponível em:

http://portal.mec.gov.br/seesp/arquivos/pdf/salamanca.pdf. Acesso em: 10 jul. 2019.

FEITOSA, Socorro. Entrevista cedida pela Coordenadora do Centro de Arte da Secretaria Municipal de Educação de Cabedelo. Cabedelo, PB: não publicada, 2015.

MANTOAN, Maria Teresa Egler. Todas as crianças são bem-vindas à escola. Revista Profissão Docente, Uberaba, v. 1, n. 1, p. 1-19, maio./ago. 2001. Disponível em:

http://www.revistas.uniube.br/index.php/rpd/article/view/32/515. Acesso em: 10 jul. 2019.

PARAÍBA. Senso escolar de $\mathbf{2 0 1 5}$ da Prefeitura Municipal de Cabedelo. Cabedelo: Secretaria Municipal de Educação. Cabedelo, PB, 2015.

SATO, Carlos; CARDOSO, Ana Maria; TOLOCKA, Rute Estanislava. A inclusão de pessoas com necessidades educativas especiais nas escolas regulares: receio ou coragem? In: VENÂNCIO, Silvana; AUGUSTO, Dulce Inês L. S. Pedagogia do movimento: coletânea de textos. Campinas: Unicamp/FEF/DEM, 2002.

UNESCO. Declaração mundial sobre educação para todos: satisfação das necessidades básicas de aprendizagem. Jomtien, 1998. Disponível em:

https://unesdoc.unesco.org/ark:/48223/pf0000086291_por. Acesso em: 10 jul. 2019. 